\title{
"WE DON'T WANT TO STAND OUT, YET SOME OF US DO": THE EXPERIENCES AND RESPONSES OF GENDER COUNTER- NORMATIVE STUDENTS AT STELLENBOSCH UNIVERSITY
}

\author{
A. Beukes* \\ e-mail: almazbeukes@gmail.com
}

\section{D.A. Francis*}

e-mail: dafrancis@sun.ac.za / https://orcid.org/0000-0001-6353-4120

*Department of Sociology and Social Anthropology

Stellenbosch University

Stellenbosch, South Africa

\section{ABSTRACT}

In 2016, The trans ${ }^{*}$ Collective student activist group brought to light the erasure of gender counternormative students' contributions to the success of the \#RhodesMustFall movement in 2015. Equally important, the Trans University Forum released a report in 2017 that compiled the experiences of gender counter-normative individuals at seven South African higher education institutions. The report evinced that universities are sites that marginalise and alienate gender counter-normative staff, students and workers. Employing life history research, the present article explores the experiences and responses of three gender counter-normative Stellenbosch University students as they navigate the university environment. Drawing on queer theory, the article highlights their challenges while at the same time it emphasises their agency and strategies of resistance to tackling cis-heteronormativity. The article concludes by highlighting how gender counter-normative students acknowledge and incorporate their relationships with others, allies and their communities as a collective response and action - collective agency - to challenge the normative, and sometimes adverse, university space.

Keywords: cis-heteronormativity, gender counter normative, life history research, university, South Africa, collective agency

\section{INTRODUCTION}

March 2015 saw the inception of the \#RhodesMustFall (\#RMF) movement when a group of predominantly black students at the University of Cape Town (UCT) engaged in protest demanding the removal of a statue of Cecil John Rhodes from the university campus (Ndelu, Dlakavu and Boswell 2017). The statue represented a symbol of the lack of transformation at higher education institutions, a symbol of continued colonial and apartheid legacy at higher education institutions and the institutional racism present at UCT (Nyamnjoh 2016). Relatedly, 
and from an economic perspective, Hlatshwayo and Fomunyam $(2019,69)$ argue that the statue also represented the economic exclusion and financial distress that many students experience. A related and equally important initiative to \#RMF was the \#FeesMustFall (\#FMF) movement that originated at the University of the Witwatersrand (Wits) in October 2015. The catalyst for the \#FMF movement comprised the proposed 10.5 per cent fee increase for the following academic year of 2016 (Ndelu et al. 2017; Andestad 2018).

The nation-wide protests resulted in "a government directive" (Ndelu at al. 2017, 2; Langa 2017) for a 0 per cent student fee increase at universities in 2016. The provisional victory led to a resurgence of the movement in 2016 as students demanded free and decolonised education across higher education institutions. For all the successes of \#RMF and \#FMF, the movements also saw an emergence of incidents of heterosexism, sexism, homophobia and transphobia in various degrees and to various extents across the different higher education institutions (Langa 2017; Ndelu 2017a).

Heterosexism, sexism, homophobia and transphobia also comprise the characteristics that impaired the \#FMF movement in particular (Ndelu et al. 2017). For example, following the \#FMF and \#RMF movements, gender counter-normative students at several South African universities have communicated negative experiences of their participation in the aforementioned student movements (Wagner 2016; Omar 2016; Collison 2016; Ndelu 2017a). To illustrate, in March 2016, transgender and gender non-binary activists at UCT protested against the harassment, exclusion, underrepresentation and censorship of gender counternormative students during the \#RMF movement (Wagner 2016). Members of The trans* Collective activist group at UCT prevented the opening of an exhibition as they expressed that they were "systematically side-lined in RMF structures" (Omar 2016). The exhibition was jointly curated by the \#RMF movement and the university's Centre for African Studies, and featured photographs from the student led \#RMF protests. The trans* Collective, comprising an activist group of gender diverse organisers from within the \#RMF movement, staged a nude protest to underscore their "disillusionment with \#RhodesMustFall's trans exclusion and erasure" (Ndelu 2017a, 72).

The outline above provides insight into how gender counter-normative student activists have experienced two of the recent significant South African student activist movements. Gender diverse student activists revealed that the initiatives operated to marginalise them, their voices and their contributions to the movements. Moreover, the outline above demonstrates the collective action of The trans* Collective activist group in asserting their role in contributing to the \#RMF movement and opposing the erasure and marginalisation that they endured during and following the \#RMF movement. Their activism furthermore put pressure on UCT to be 
more inclusive of gender-diverse students and staff members (Ndelu 2017b).

It is against this backdrop that the present article analyses the life histories of three gender counter-normative students at Stellenbosch University (SU). More specifically, it is concerned with how gender counter-normative students have experienced and navigated SU following the nationwide stream of the \#RMF and \#FMF movements. Because our participants identified as transgender or gender non-binary we use the term gender counter-normative. We use "counternormative", instead of "non-normative", when referring to people whose gender identity and/or expression is different to that typically associated with their assigned gender at birth. "Non-" implies that individuals are absent, negated, erased and invisible (Francis 2017a). Instead we use "counter-normative" intending to not only affirm the navigational capabilities of gender diverse individuals and their experiences, but also to emphasise the agency that individuals undertake in challenging the heterosexual matrix, cis-normativity and the gender essentialism represented by the hegemonic gender binary.

\section{GENDER EXPRESSION AND QUEER THEORY}

Attempts at gender expression oppression comprise trans-antagonistic encounters, discrimination and harassment that effects the alienation and marginalisation of individuals with counter-normative gender identities and expressions. At an individual level, individuals can act as agents of gender expression oppression by displaying trans-antagonistic attitudes and/or engaging in trans-antagonistic behaviours. At an institutional level, the structural design and institutional culture of an establishment and its constituent structures can reflect and enforce prescriptive cisnormative assumptions and standards of gender. Institutions that reflect and enforce the taken for granted legitimacy of cisnormativity are therefore conducive to the perpetuation of gender expression oppression. The present article, however, does not present gender counter-normative individuals as mere subjects of gender expression oppression. The article deliberately prioritises the agency of gender diverse SU students as they resist attempts at and experiences of gender expression oppression within the university context.

Counter-normative spaces represent spaces that facilitate the resistance of gender expression oppression. Similarly, counter-normative networks represent networks that contribute to the resistance of gender expression oppression. Counter-normative spaces take the form of university support structures and associations that the students interviewed have reached out to and frequented. Counter-normative networks comprise friend, family, community and advocacy groups that the students belong to.

Queer theory grapples with constructs such as power, oppression, normativity, counternormativity, agency, and resistance - especially as it relates to gender and sexualities. Queer 
theory questions who is oppressed by normative systems, and exposes the illegitimacy of normative social orders, systems and practices. The present article draws on queer theory and specifically Butler's (1999) writing on the heterosexual matrix.

The heterosexual matrix represents the hegemonic social order that presupposes that individuals intrinsically possess a fixed gender and sexual identity. Furthermore, and often formulated as the sex-gender-desire order, the heterosexual matrix accounts for the societal assumption and expectation that biological sex determines gender identity and gender identity determines sexuality or sexual desire. The conventions of masculinity and femininity represent normative gendered expectations associated with the male and female binary. Therefore, one is expected to conform to the gender binary by performing gender in an either stereotypical masculine or feminine manner, as deemed in line with one's assigned biological sex. Framed in opposition to one another, males and females are furthermore expected to express a sexual desire for the opposite sex. On the whole, the heterosexual matrix operates to sustain the gender binary.

We, therefore, draw on Butler's (1999) heterosexual matrix because it challenges the notion that masculinity and femininity exists in opposition to one another. These conventions have no biological basis and are merely socially constructed. This suggests that the heterosexual matrix and the gender binary as a structure is unreliable. Queer theory exposes these gender binaries as hierarchical systems that have unequal power relations at their cornerstone. As such, individuals with gender and sexual identities that do not align with cis-heteronormative expectations are marginalised. As it pertains to the present article, gender counter-normative individuals construct and express their gender identity in a way that does not align with their assigned sex at birth, thereby subverting the heterosexual matrix that operates to sustain the current gender hegemony.

\section{SOUTH AFRICAN HIGHER EDUCATION INSTITUTIONS: GENDER EXPRESSION OPPRESSION AND RESISTANCE}

Hames $(2007,68 ; 2016,186)$ argues that the heteronormative nature of South African higher education institutions creates a campus climate that is not welcoming, nor is it adequately prepared, to meet the needs of lesbian, gay and transgender people. A study by Cornell, Ratele and Kessi (2016) set out to explore students' experiences of transformation at UCT. The authors found that students who are LGBTQI ${ }^{1}$, as well as black, women and working-class students, were frequently subjected to instances of both physical and symbolic violence.

One of the students interviewed described the discourse at UCT as positioning their "ideal student" as white, male, cisgender, able-bodied and middle class. For them, this was a form of 
symbolic violence, as any student who diverges from the token "ideal student" could be subjected to alienation and marginalisation. Other forms of symbolic violence for gender diverse students included many of the UCT residences that endorse cisgendered assumptions about gender and are segregated along the lines of a gender binary. Cornell et al. (2016) also point to the lack of notably visible and easily accessible gender-neutral bathrooms as another form of symbolic violence that targets gender diverse students.

Considering this, Cornell et al. (2016) concluded that the heteronormativity and cisnormativity embedded in the residence culture and represented in the structure of most campus bathrooms render the students who are perceived to transgress those norms to be subjected to scrutiny and abuse. The authors, however, emphasise that students that diverge from the aforementioned "ideal student" have disrupted - and are able to disrupt - instances of especially symbolic violence. Students have disrupted instances of symbolic violence by "using their own bodies or identities as a site of resistance or physically changing campus spaces" (Cornell et al. 2016, 115), notably in the form of protest movements. The previously mentioned protest demonstration by The trans* Collective serves as an example of resistance against symbolic violence that especially gender diverse students have endured.

A report (Ndelu 2017b) compiled by the Trans University Forum (TUF!) ${ }^{2}$ reflects the experiences, needs and wants of gender counter-normative students and staff members at seven ${ }^{3}$ South African universities. The report reveals accounts of discrimination, alienation, marginalisation, and trans-antagonistic harassment and violence across all of the universities investigated. The students interviewed also reported their overall disillusionment with the institutional structures of their respective universities. The report furthermore emphasises the activist campaigns initiated by gender diverse staff and students. More specifically, the report credits The trans* Collective for their protest against the harassment, exclusion, underrepresentation and censorship of gender counter-normative students. According to the report, the activism incited by The trans* Collective put pressure on UCT to be more genderinclusive and recognise the needs of gender counter-normative staff members and students.

In addressing the University of the Free State and Wits University, the report explains that gender diverse student and staff activists at these universities "successfully advocated for their universities to have accessible gender-neutral bathrooms across all their campuses" (Ndelu $2017 \mathrm{~b}, 11)$. This intervention was accompanied by "an extensive awareness campaign to sensitise the broader university community on gender diversity" (Ndelu 2017b, 11). In 2016, Wits University gender diverse activists successfully campaigned for the university to commit to affirming gender diversity at the university. Whilst appreciating the aforementioned activist campaigns, the report warns that the successes of the campaigns should not be mistaken as an indication that South African universities are safe, welcoming and "non-antagonistic" spaces 
for gender diverse students.

A study conducted by Matthyse (2017) focuses on the challenges that homophobic and transphobic oppression, prejudice and discrimination pose to sexual and gender diverse University of the Western Cape students. Matthyse explores his $^{4}$ own experiences as a "LGBTIQ" identifying student, student leader of an LGBTIQ student organisation, and subsequently as a university administrative staff member working with LGBTIQ identifying students" (Matthyse 2017, 113). Matthyse argues that advocacy and awareness-raising are effective tools to utilise in challenging homophobic and transphobic prejudice, discrimination and oppression. Matthyse, however, makes it clear that the impact of the aforementioned tools are influenced by the role that "institutional functionaries" play in ensuring the efficacy of these tools, as the institutional functionaries "hold the power ... to affect direct policy transformation" (Matthyse 2017, 124). To further illustrate the author's position:

"The two approaches should be mutually complementary, with awareness-raising stimulating transformation from the bottom up, while progressive policy and decision-makers stimulate transformation from the top down" (Matthyse 2017, 124).

The advocacy and awareness-raising initiatives under the Gender Equity Unit at UWC, along with Matthyse's call for collaboration between the stakeholders of the initiatives and the policy decision-makers, constitute a call for collective action in necessitating effective gender and sexual diverse inclusive institutional change. In a broader sense, Matthyse's position is useful in considering the potential of collective agency (Francis and Reygan, 2016) in creating inclusivity, or spaces of counter-normativity, for sexual and gender diverse students within the context of any South African university.

South African research on the experiences of gender diverse students and staff at higher education institutions, therefore, observes the actions of gender diverse students and staff as they have opposed the marginalisation imposed on them. Additionally, the research reviewed observes the actions that the students and staff have taken in mitigating the harmful effects that gender expression oppression may have had on gender diverse individuals at the universities discussed. The literature also calls for the raising of people's awareness and consciousness related to LGBTIQ concerns, and advocates for social, structural and policy transformation.

\section{METHOD}

\section{Data collection}

Life history interviews (Seidman 1991) was the primary data collection technique. The first author adapted and conducted three separate open-ended, semi-structured interviews as 
prescribed by Seidman $(1991,10)$. The intention of the life history interviews was to explore the respondents' experiences, and to situate these experiences within their contexts. The interviews focused on the participants' life experiences prior to entering university, their life experiences whilst at university, and the meaning that they made of these life experiences. In line with the focus and scope of the present article, the article primarily presents the participants' experiences at SU. All interviews were conducted by the first author from November of 2017 to August of 2018.

\section{The participants: Valerie, Aphiwe and Lesedi}

The study utilised both purposive sampling and snowball sampling to recruit participants. The first participant Valerie, a coloured ${ }^{6}$ transgender woman, shared a connection with the first author on a social media platform - namely Instagram. Valerie publicly proclaimed her gender identity on her Instagram profile and the first author made contact via this platform. Valerie grew up in the Cape Flats ${ }^{7}$ area. Although she moved around a lot with her mom as a child, she completed her primary school career at the same school, as they were still broadly living in the same area. Valerie, however, changed schools in high school. She attended a high school in Retreat for grade 8 and 9 and subsequently moved to another school in Constantia for the remainder of her high school career. Valerie enrolled for a Bachelor of Science degree for her first year at SU but discovered that it was not for her. Subsequently, she enrolled for a Bachelor of Arts degree for her second year. At the time of our interviews, Valerie was completing her final year of undergraduate studies. She was also working as an intern at a student support office at the university. Valerie's chosen pronouns are she, her, and hers.

The second participant, Aphiwe, is a black gender non-binary student and familiar to both authors. Aphiwe was born, grew up in and went to school in the Eastern Cape. They attended primary school and lived with their grandmother in a "semi-rural area" up till grade 9. Aphiwe went to high school after grade 9 and also moved in with their mother at this time. After matriculating in 2011, Aphiwe enrolled in an Information Technology course, but changed direction soon after and completed a business course. They then decided to enrol for a Bachelor of Arts degree at SU with the goal of studying philosophy. At the time of the interviews, Aphiwe was a postgraduate Honours student within the Arts and Social Sciences faculty. Aphiwe's chosen pronouns are they, them, and theirs.

Third is Lesedi, a black transgender woman who was introduced to the first researcher by Valerie. She grew up in a village in Limpopo where she also started and completed her primary school and high school careers. Lesedi expressed her gender identity from an early age, but as she neared her teenage years, she explained that "I kind of moulded myself into what society 
expects". She kept her gender identity secret throughout her teenage years and found refuge in her high school academics. Lesedi set her sights on studying at a university far away from home, as she was convinced that being on her own would allow her "to unashamedly discover and embrace her authentic self". After matriculating she commenced her tertiary education at SU in 2015. At the time of our interviews, in 2018, she was a third-year Engineering student. Lesedi looked forward to graduating at the end of 2019 and starting her career soon thereafter. Lesedi's chosen pronouns are she, her, and hers.

\section{Analysis}

The analysis of the life histories comprised the combined utilisation of thematic analysis (Seidman 1991; Attride-Stirling 2001) and within and cross-case analysis (Merriam 1998; Ayres, Kavanaugh and Knafl 2003). Within-case analysis required each transcribed life history to first be "treated as a comprehensive case in and of itself". In conducting the within-case analyses, thematic analysis was used to identify and report the noteworthy themes within the textual data. Following Seidman's (1991) description of an analytic approach to life history research, the first author identified the categories and subsequently compared these categories to identify certain themes as they emerged from the data. In conducting the cross-case analysis, the general commonalities across the life-histories were identified and analysed (Merriam 1998; Ayres et al. 2003). As deemed relevant, the variances between the cases were also considered. A consideration of the commonalities and variances between the cases was done to arrive at a general synthesised explanation that captures the essence of the participants' experiences.

\section{Ethics}

Ethical clearance to commence the study discussed in this article was received from the Research Ethics Committee at Stellenbosch University. To maintain anonymity and confidentiality, pseudonyms are used in the discussion of findings when all three respondents are referred to or quoted.

\section{FINDINGS}

The findings, comprising the themes gender expression oppression, counter-normative spaces and networks, and individual and collective agency and resistance are presented below.

\section{Gender expression oppression}

In sharing their experiences, the participants noted how staff and students at university responded to their observable counter-normative gender expressions. With reference to their 
participation in the \#FMF movement at SU, Valerie and Aphiwe recall how counter-normative student activists were invisibilised, noting that there was a "silencing" of black women, queer women and transgender women. Beyond the \#FMF movement, the erasure and censorship of gender diverse students within the university context was a significant feature of the participants' accounts. To illustrate, the invisibilisation of transgender student leaders was of particular concern to Lesedi. This concern stems from her own experience when she availed herself for the position of Cluster Convener ${ }^{8}$ in 2017 :

“... I can recall when I went for a caucus, for Cluster Convener ... One of my friends were sitting in the audience, and a bunch of these Afrikaner guys, someone told them that I'm a transgender woman. And they started 'attacking' me with questions on the stage ... and what made them [angrier] was that I was calm ... and confident, I always answered them. I feel like it threatened them ... because we are taught to be ashamed of our identity, we are taught to be smaller and I'm not."

Lesedi's account highlights how transgender individuals are discriminated against, harassed and excluded from opportunities that should be afforded to all students.

Besides the participants accounts of their and others' counter-normative gender expressions being met with attempts at coerced invisibility, the participants also conveyed a desire to remain "invisible" at times when their gender identity and expression was treated as a "spectacle". Aphiwe, for example, upon reflecting on people's reactions to their ambiguous gender expression, explained that people tend to treat their gender identity and expression as a "spectacle". Valerie, too, expressed experiences where her visibility as a transgender woman was met with discrimination. For instance, Valerie explained that one of her lecturers continuously misgendered her and during one of the lectures she explained to the lecturer how disrespectful it was. As the lecturer was educating the class on the term "misogynoir", Valerie drew on "transmisogyny" as a parallel to "misogynoir". She did this to explain to the lecturer that she was being "transmisogynistic" in continuously misgendering her. This and other transantagonistic experiences led her to intentionally avoid attracting unwanted attention to herself when attending lectures. She explains

"But I find the same thing with the use of pronouns, we [trans students] don't want to be referred to so we don't participate in class. So that's, like, the one reason for it. And then the other reason would be that we would just be spotlighted, you know, we would just be drawn attention to. And for trans people it's more about blending in. We don't want to stand out, yet some of us do. Ja, usually classes are supposed to be safe spaces but ... I find that lecturers and teachers don't know how to deal with trans people or students, you know, in general." 
All three participants mentioned that academic, administrative and support staff at SU must raise their awareness of and accommodate gender counter-normative students. As it pertains to the participants' experiences and observations highlighted thus far, raising awareness and accommodation entails learning more about and interacting with gender counter-normative students in a manner that ceases to treat their gender diversity as a spectacle.

\section{Counter-normative spaces and networks}

Aphiwe expressed that their self-concept is tied to an "open/fluid sense of identity". This selfconcept is rooted in how they were brought up and how their family responds to them. Reminiscing about their childhood, Aphiwe recalls that they "[moved] through every space with ease", primarily because they did not "think of [themself] in gendered terms". Aphiwe acknowledges that being surrounded by "a lot of love and support and encouragement" from their family secured their sense of safety. This therefore also secured their ability to freely move between spaces that represent the rigidity of the gender binary without fear of judgment or regulation. Furthermore, Aphiwe continues to utilise their gender ambiguity to their advantage to move between gender categories and spaces that are structured in a gender-specific manner.

Subverting the gender-specific binary in this way aligns with Valerie's assertion that gender diverse students' ability to create safe spaces for themselves contributes to the visibility of gender diverse individuals. To further illustrate this point, Lesedi used her position as a member of an on-campus transformation committee to advocate for the implementation of gender-neutral bathrooms. According to Lesedi, serving on this committee allows her to "have a voice" where the other members of the committee "listen to [her]". The committee was awaiting a reply from the university council regarding their petition at the time of the interviews with Lesedi. The relation between an association to a counter-normative network and the creation of counter-normative spaces thus becomes clear.

The participants also encountered certain spaces and belonged to certain networks at the university that have left them with paradoxical impressions. In recalling her experiences at the LGBTQI+-centred events hosted by the LesBiGay ${ }^{9}$ society and the Equality Unit ${ }^{10}$, Lesedi expressed that the visibility of other "out" gender diverse individuals at the events empowered her. However, she also noted that the LesBiGay society tended to neglect issues pertaining to gender diverse individuals. This suggests that even counter-normative spaces and networks have the potential of engaging in exclusionary practices. Conversely, she credits her lecturers and fellow classmates for respecting her gender identity.

Valerie, too, encountered certain spaces at the university as being exclusionary in some regards, whilst simultaneously being counter-normative in other regards. As a first-year student 
in Murray Residence ${ }^{11}$ - a single-sex male residence - in 2014, Valerie, to her surprise, found that the residents welcomed her into the residence space. She explains that they "saw that I was a queer body when I came in immediately and ... that recognition, it made things easier". Valerie also met another first-year transgender woman resident during welcoming week ${ }^{12}$ and they became friends who supported and relied on one another. Contrarily, Valerie's assigned roommate displayed trans-antagonistic reactions towards her. Her roommate insinuated that Valerie was going to "prey" on him. This disagreeable experience prompted Valerie to approach the residence head who arranged for her to share a room with another roommate who, unlike the first assigned roommate, did not contribute to an uncomfortable living arrangement.

The participants' accounts shed light on the ways in which counter-normative spaces and networks challenge gender expression oppression. At the same time, however, these accounts underscore that the university space is not exempt from sustaining gender expression oppression and marginalisation.

\section{Individual agency and resistance}

The findings also convey that acts of resistance take on various and nuanced forms. Although the methods of resistance differ, the participants' ability to enact resistance demonstrates their agency and resilience in navigating and overcoming the challenges imposed by the heterosexual matrix.

The participants shared many stories of trans-antagonistic encounters. In telling these stories they have revealed that they typically maintain their composure and disregard others' attempts to make them feel ashamed of their gender counter-normative expressions. In doing so, the participants refuse to succumb to the attempted regulation and punishment of their gender identities and expressions. Attempts at regulation and punishment constitute oppressive strategies intended to coerce individuals who exhibit and enact gender counter-normative expressions to conform to cisnormative expectations. A refusal to succumb to attempts at regulation and punishment furthermore displays rejection of cisnormative expectations and the overall cisnormative structure. This, at the same time, troubles the presumed legitimacy of cisnormativity and demonstrates the fragility of the cisnormative structure. Considering Butler (1999), the abovementioned examples of participants' agentic resistances to cisheteronormative standards and expectations also troubles the presumed legitimacy of the heterosexual matrix and exposes its fragility.

The findings, for example, detail how the participants have had to take on the role of an educator in responding to agents of gender expression oppression. In educating perpetrators of gender expression oppression, they challenged the cis-heteronormativity that pervaded these 
environments. As previously mentioned, Lesedi served as a member of an on-campus transformation committee where she advocated for the implementation of gender-neutral bathrooms. Lesedi demonstrated her agency by choosing to engage in advocacy aimed at securing safe spaces for gender diverse students. Here, following her own experience of transantagonistic harassment, she used her voice to advocate for one of the ways in which the university can adequately accommodate and include gender counter-normative staff and students. She is thus influential in the potential establishment of structural counter-normative spaces within the university context. Taken altogether, the students have demonstrated that they have navigated oppressive spaces in ways that have enabled them to create counter-normative spaces for themselves and other gender diverse individuals.

The participants therefore also become instrumental in - and even become pioneers in creating counter-normative spaces. All in all, they utilise their gender ambiguity to their advantage to move between gender categories and spaces that are structured in a gender-specific manner. Their gender counter-normative actions and expressions therefore expose the presumed legitimate divisions of binary gender-specific categories and spaces as fictitious and unreliable.

The present section has thus far delineated the innovative, pedagogical and advocative methods of resistance that the participants enacted in opposition to the hegemony of the cisheteronormative structure. Considering, again, the topic of counter-normative spaces and networks, the article now further considers how the participants belong to and draw on various support networks. In doing so the link between counter-normative spaces and networks and collective agency is also introduced.

\section{Collective agency and resistance}

The individual agency of the participants at times coincides within the context of collective agency. Their ability to change their circumstances for the better relied on engagement with others and a sense of belonging to a community. For Lesedi, being part of a transformation committee better allowed her to launch her initiative to start creating counter-normative spaces. As already mentioned, Valerie and Aphiwe, too, participated in the \#FMF movement, which indicates that they engaged with others in collective advocacy. The friendship, familial, community and advocacy networks that the participants belong to are characterised by camaraderie, love, security, support and encouragement. The connections of the participants to their family, friends and other allies position them as part of networks that validate them. By extension, these networks also validate the participants' identities as gender counter-normative individuals. As such, the members of the participants' friend, family, community and advocacy 
groups establish these groups as counter-normative networks.

Aphiwe, for instance, explained that their family has always accordingly responded to their gender counter-normative expression. Their belonging to this counter-normative network played a part in the participant's ability to construct and express their gender identity outside of the limitations perpetuated by the heterosexual matrix. Furthermore, Aphiwe enacts their agency by moving between gender-specific categories and spaces with ease. They therefore expose binary gender classifications and divisions as fictitious and fallible. They thus also subvert the perceived and imagined validity of the heterosexual matrix. The counter-normative actions that Aphiwe enact not only demonstrates their agency as a resistor of the normative structure perpetuating the heterosexual matrix, but also contributes to the formation of counternormative spaces that further subverts the heterosexual matrix.

To reiterate, the participant's current independent capability to subvert the cisheteronormative structure by transcending its boundaries can be traced back to the collective agency of their family. As a counter-normative network, their family facilitated the counternormative spaces that made it easier for the participant to resist the heterosexual matrix. Collectively, Aphiwe's family were thus to some extent also instrumental in resisting the heterosexual matrix.

In addition, although the \#FMF movement at SU essentially overlooked gender counternormative students, the literature reviewed in this article provides examples of the potential of collective student advocacy to facilitate institutional change at higher education institutions. Moreover, the present article argues that SU has the potential to transform itself into an overall counter-normative institutional space. Borrowing from Matthyse (2017), collective advocacy therefore appears to be effective in facilitating institutional change aimed at creating gender diverse-inclusive and gender diverse-accommodating spaces. In bringing this section of the findings to a close, the participants' narratives make it clear that collective action is necessary to further create and sustain counter-normative spaces, and to bring about broader institutional and societal change.

\section{DISCUSSION}

In bringing this article to a close, the following can be discerned.

Firstly, the present article highlights the agency of the participants as they have demonstrated their resistance to the gender expression oppression that they encounter. In light of this, the present article presents the varying and nuanced nature of the range of the participants' individual agentic resistances against the heterosexual matrix. These resistances took the form of innovative, pedagogical and advocative strategies as employed by the 
participants to counterbalance incidents and experiences of gender expression oppression. The individual agency of the participants reveals their capabilities to, on the one hand, enact their resilience in the face of the heterosexual matrix and, on the other hand, contribute to the creation of counter-normative spaces. Resilience in the face of the heterosexual matrix, and in being responsible for the formation and maintenance of counter-normative spaces, disrupts the cisheteronormative structure that pervades SU in particular.

Secondly, the participants drew on broader frameworks of familial networks, fellowship, assistance and community to augment their capacity for individual agentic resistance. The actors comprising these friendship, familial, community, activism and other university support networks are also regarded as agents in creating and maintaining counter-normative spaces. Additionally, recognising the individual participants' affiliations with support networks, and interactions with the collective, the article thus accounts for the influence of both individual agency and collective agency in challenging the cis-heteronormative structure. The present article also asserts that the transformative potential of collective agency is greater than the transformative potential of individual agency, as collective action is better suited to affect institutional change.

Finally, queer theory's prioritisation of individual agency in the face of marginalisation, although useful, has been shown to be limited in South African contexts for neglecting to prioritise the collective networks that individuals interact with and form part of. The present article thus evaluates the individual agency of the participants as it coincides with the collective agency of the networks they belong to. A bridging of the literature reviewed and the theoretical framework employed for the present study demonstrate that collective advocacy is necessary to facilitate the institutional change necessary to create counter-normative spaces and contribute to counter-normative networks. Furthermore, the adoption of a queer, intersectional framework would constitute a more holistic approach to transformation policies and scholarship in higher education institutions (Francis 2016; 2019; Msibi 2013). The present article, therefore, affirms queer theory's focus on individuals that resist the presumed legitimacy of normative social orders, systems and their related strategies. It extends the aforementioned focus of queer theory by recognising that the participants, as individuals, belong to and engage with collective groups (Francis 2017b; Francis and Reygan 2016). The unique contribution of this article acknowledges the transformative potential of individual agency, and the wide-reaching transformative potential of collective agency. It observes both forms of agency in their ability to challenge oppressive structures and systems, and resultant forms of gender expression oppression and other forms of marginalisation and discrimination. 


\section{IMPLICATIONS}

In investigating how gender diverse students navigate university, it becomes apparent that gender expression oppression pervades the university environment. Resulting in unwelcome and alienating spaces for gender diverse students, universities should work towards addressing gender and sexuality diversity. Implications of the present article for universities indicate a need for their institutional policies and related transformation strategies to incorporate a queer, intersectional framework as proposed by queer scholars (see Francis 2016; 2019; Msibi 2013). A queer, intersectional approach to policy development would account for the historical and social conditions unique to the university context. How these conditions relate to the various normative structures embedded in the university, how these normative structures converge, and how the convergence of these normative structures factor into the lived experiences of students and staff - also considering the range and intersections of their social categories - would offer a more inclusive, holistic approach to transformation.

Relatedly, there is a critical need for universities to adopt a queer, intersectional approach to curriculum (Francis and Kuhl 2020). A queer, intersectional approach to curriculum will trouble the oppressive nature of gender expression oppression embedded in, and perpetuated by, the structural design and institutional culture of the university context. This entails the development of learning environments - not to be confined to the classroom - that educate academic, administrative and support staff and students on issues of gender diversity and adequately sensitise academic, administrative and support staff to the experiences and needs of gender diverse individuals.

Finally, drawing on Matthyse (2017), a serious commitment to the effective implementation of queer, intersectional approaches to transformation and curriculum is crucial. This commitment should thus be upheld by all functionaries responsible for the development and implementation of institutional policies and strategies. In other words, the transformation of universities rests on the collective response of university management; academic, administrative, and support staff; and relevant leadership bodies in ensuring that queer, intersectional transformation policies, strategies and curriculum are effectively implemented.

\section{NOTES}

1. Lesbian, Gay, Bisexual, Transgender, Queer or Questioning, Intersex.

2. Formerly known as The trans* Collective, TUF! "is a movement of gender activists that advances the inclusion and affirmation of trans people at all 26 South African universities and universities of technology" (Trans University Forum 2017).

3. The University of the Witwatersrand, Stellenbosch University, Rhodes University, Nelson Mandela University, the University of the Free State, Sol Plaatje University and Durban University of Technology (Ndelu 2017b). 
4. The author's (Matthyse 2017, 113) self-designated gender-neutral pronoun.

5. Lesbian, Gay, Bisexual, Transgender, Intersex, Queer or Questioning.

6. The participants self-identified in terms of racial categories when describing themselves or recounting certain experiences. In mentioning racial categories - "white", "black" and "coloured" - we understand these as social constructs and not as something fixed and essential.

7. The Cape Flats is situated on the outskirts of Cape Town's city centre.

8. A student leader "who assists ... with all the activities in a cluster", whereby a "cluster" refers to "a group of residences that are grouped together primarily on a geographical basis and to which a PSO ward (in the case of an integrated men's and women's ward) or two PSO wards (in the case of separate men's and women's wards) are allocated to form a student community ..." (Stellenbosch University 2013, 8).

9. The LesBiGay student society at SU "strives to serve students identifying within the Queer community in a manner that is compassionate, dignified and supportive" (LesBiGay 2019).

10. The Equality Unit at SU "coordinate[s], educate[s] and raise[s] awareness around sexualities, gender, HIV/Aids, sexual harassment and anti-discrimination ... [and] deliver[s] [these] services and support to students, faculty and staff at SU" (Equality Unit 2019).

11. Pseudonym.

12. The orientation programme for first-year students entering SU preceding the beginning of the first term of the academic year.

\section{REFERENCES}

Andestad, S. 2018. The role of racial division in the \#FeesMustFall movement: Exploring students' personal experiences of the protests and the racial division in the \#FeesMustFall movement in South Africa. Oslo and Akershus, Norway: Oslo Metropolitan University.

Attride-Stirling, J. 2001. Thematic networks: An analytic tool for qualitative research. Qualitative Research 1(3): 385-405.

Ayres, L., K. Kavanaugh and K. Knafl. 2003. Within-case and across-case approaches to qualitative data analysis. Qualitative Health Research 13(6): 871-883.

Butler, J. 1999. Gender trouble: Feminism and the subversion of identity. New York: Routledge.

Collison, C. 2016. \#FeesMustFall "burns” queer students. Mail \& Guardian 14 October.

Cornell, J., K. Ratele and S. Kessi. 2016. Race, gender and sexuality in student experiences of violence and resistances on a university campus. Perspectives in Education 34(2): 97-119.

Equality Unit. 2019. http://www.sun.ac.za/english/learning-teaching/student-affairs/cscd/equalityunit/ about-us (Accessed 22 September 2019).

Francis, D. and F. Reygan. 2016. Relationships, intimacy and desire in the lives of lesbian, gay and bisexual youth in South Africa. South African Review of Sociology 47(3): 65-84.

Francis, D. 2016. "I felt confused; I felt uncomfortable ... my hair stood on ends": Understanding how teachers negotiate comfort zones, learning edges and triggers in the teaching of sexuality education in South Africa. In Global perspectives and key debates in sex and relationships education: Addressing issues of gender, sexuality, plurality and power, ed. V. Sundaram and H. Sauntson, 130-145. Palgrave Macmillan UK. http://dx.doi.org/10.1057/9781137500229_9

Francis, D. 2017a. "I think we had one or two of those, but they weren't really": Teacher and learner talk on bisexuality in South African schools. Journal of Bisexuality 17(2): 1-19. https://doi.org/10.1080/15299716.2017.1326998

Francis, D. 2017b. TROUBLING the teaching and learning of gender and sexuality diversity in South African education. Palgrave Macmillan.

Francis, D. 2019. "Oh my word; for us African gays it's another story." Revealing the intersections 
between race, same sex-sexuality and schooling in South Africa. Race Ethnicity and Education, 1-17. https://doi.org/10.1080/13613324.2019.1679752

Francis, Dennis A. and Kylie Kuhl. 2020. "Imagining a curriculum beyond compulsory heterosexuality in South African education." Journal of LGBT Youth: 1-20. doi: https://doi.org/10.1080/ 19361653.2020.1844606

Hames, M. 2007. Sexual identity and transformation at a South African university. Social Dynamics 33(1): 52-77.

Hames, M. 2016. Black feminist intellectual activism: A transformative pedagogy at a South African university. Cape Town, South Africa: University of Cape Town.

Hlatshwayo, M. N. and K. D. Fomunyam. 2019. Theorising the \#MustFall student movements in contemporary South African higher education: A social justice perspective. Journal of Student Affairs in Africa 7(1): 61-80. DOI: 10.24085/jsaa.v7i1.3693.

Langa, M. 2017. Researching the \#FeesMustFall movement. In An analysis of the \#FeesMustFall movement at South African universities, ed. M. Langa, 6-12. Johannesburg: Centre for the Study of Violence and Reconciliation.

LesBiGay. 2019. http://www.sun.ac.za/english/students/studentsocieties/social-awareness-societies/ lesbigay (Accessed 22 September 2019).

Matthyse, G. 2017. Heteronormative higher education: Challenging the status quo through LGBTIQ awareness-raising. South African Journal of Higher Education 31(4): 112-126.

Merriam, S. 1998. Qualitative research and case study applications in education. San Francisco, California: Jossey-Bass.

Msibi, T. 2013. Queering transformation in higher education. Perspectives in Education 31(2): 65-73.

Ndelu, S. 2017a. "A rebellion of the poor": Fallism at the Cape Peninsula University of Technology. In An analysis of the \#FeesMustFall movement at South African universities, ed. M. Langa, 13-32. Johannesburg: Centre for the Study of Violence and Reconciliation.

Ndelu, S. 2017b. In their voices: Being (trans)gender diverse at a South African university. Trans University Forum (TUF!). Cape Town, South Africa.

Ndelu, S., S. Dlakavu and B. Boswell. 2017. Womxn's and nonbinary activists' contribution to the RhodesMustFall and FeesMustFall student movements: 2015 and 2016. Agenda 31(3-4): 1-4.

Nyamnjoh, F. B. 2016. \#RhodesMustFall: Nibbling at resillient colonialism in South Africa. Bamenda, Cameroon: Langaa Research \& Publishing Common Initiative Group.

Omar, Y. 2016. Trans collective stops RMF exhibition. https://www.news.uct.ac.za/article/-2016-03-10trans-collective-stops-rmf-exhibition (Accessed 22 September 2019).

Seidman, I. E. 1991. Interviewing as qualitative research: A guide for researchers in education and the social sciences. New York, NY: Teachers College Press.

Stellenbosch University. 2013. Policy for placement in residences, and in listening, learning and living houses, as well as allocation to PSO wards and clusters. https://www.sun.ac.za/ english/maties/Documents/Placement\%20Policy.pdf (Accessed 22 September 2019).

Trans University Forum. 2017. https://web.facebook.com/transuniversityforum/?tn-str=k*F (Accessed 7 March 2020).

Wagner, L. 2016. Naked trans protesters: Rhodes Must Fall must fall. The Times 11 March: 6. 